\title{
Fabrication of functionally graded rods with three cylindrical layers made by spark plasma extrusion (SPE) process and characteristics of each layer
}

\author{
Hiroshi IZUI*, Keisuke KANAZAWA**, Takuto WATANABE*, Hideki SHIODA* and Koichiro ABE* \\ * Department of Aerospace Engineering, Nihon University \\ 7-24-1 Narashinodai, Funabashi, Chiba 274-8501, Japan \\ ** Department of Aerospace Engineering, Graduate School of Nihon University \\ 7-24-1 Narashinodai, Funabashi, Chiba 274-8501, Japan \\ E-mail: izui.hiroshi@nihon-u.ac.jp
}

Received: 17 February 2020; Revised: 18 June 2020; Accepted: 1 September 2020

\begin{abstract}
Functionally graded (FG) rods with three layers in the radial direction were fabricated by a spark plasma extrusion (SPE) process. The FG rods consisted of a pure Ti compact in the center, a 15TiB/Ti composite layer in the middle, and a $25 \mathrm{TiC} / \mathrm{Ti}$ composite layer on the outside. Extrusion was carried out at a temperature of $1000^{\circ} \mathrm{C}$, at a pressure of $50 \mathrm{MPa}$ with extrusion ratios (cross-sectional area before extrusion/cross-sectional area after extrusion) of 2.3 (from $d_{i}=15 \mathrm{~mm}$ to $d_{o}=10 \mathrm{~mm}$ ) and 3.5 (from $d_{i}=15 \mathrm{~mm}$ to $d_{o}=8 \mathrm{~mm}$ ). An FG rod with a length of over $40 \mathrm{~mm}$ and a high relative density could be obtained by the SPE process. The cross-sectional area ratio of the pure $\mathrm{Ti}$ layer after extrusion significantly decreased compared to the $15 \mathrm{TiB} / \mathrm{Ti}$ and $25 \mathrm{TiC} / \mathrm{Ti}$ composite layers due to the higher ductility of the pure Ti. On the contrary, the cross-sectional area ratio of the $25 \mathrm{TiC} / \mathrm{Ti}$ composite layer increased after the extrusion, because the $25 \mathrm{TiC} / \mathrm{Ti}$ composite layer had quite low ductility. Due to the sufficient material flow during the extrusion, the $\mathrm{TiC}$ particles in the 25TiC/Ti composite layer of the FG rod were uniformly distributed along the extrusion direction. Furthermore, during the SPE process, the TiB clusters in the TiB/Ti composite layer were transformed into TiB whiskers, and the TiB whiskers were mainly oriented parallel to the extrusion direction. The tensile strength of the TiB/Ti composite layer fabricated by the SPE process improved due to the transformation of the TiB whiskers and their orientation along the extrusion direction.
\end{abstract}

Keywords : Functionally graded (FG) rod, Titanium matrix composites, TiB, TiC, Spark plasma extrusion (SPE) process, Microstructure, Tensile properties

\section{Introduction}

Titanium and its alloys have high specific strength, high fatigue strength and good corrosion resistance. Therefore, hundreds of thousands of titanium fasteners for slideless fixing are used on each commercial aircraft. However, their tribological characteristics are poor, and this is the main reason why these fasteners are not used for sliding components. Our previous study on a Ti matrix composite indicated that TiB-reinforced pure Ti matrix composites have high tensile strength (Kamegawa, el at., 2015), and TiC-reinforced pure Ti matrix composites have good dry sliding wear resistance (Izui, el at., 2018). However, the addition of the hard ceramic particles in the titanium matrix leads to a decrease in ductility. One way to achieve a good balance of tensile strength, wear resistance, and ductility is to fabricate functionally graded (FG) rods that consist of three concentric layers.

Functionally graded materials (FGMs) have a varying composition and microstructure along one of the linear 
dimensions, such as the thickness direction. Various production methods for FGMs have been developed, such as powder stacking, combustion processing, laser cladding, spray deposition, electron-beam physical vapor deposition, and chemical vapor deposition (Miyamoto, 1999, Kieback, 2003, and Chmielewski, 2016). For FG rods consisting of cylindrical layers, powder metallurgy is the most commonly employed fabrication technique due to its superior layer composition controllability and reliable consolidation (Tokita, 2005, and Watanabe, el. at., 2008). Among sintering processes, the spark plasma sintering (SPS) process is the most suitable for the consolidation of Ti particles and Ti particles with ceramic particles. The advantages of the SPS process include the consolidation of metallic and ceramic powders at significantly lower sintering temperatures, shorter sintering times, and higher heating rates. In particular, the SPS process is capable of consolidation, with a high relative density, of materials that are difficult to sinter, such as aluminum, titanium, titanium matrix composites, and ceramic materials. However, most of the samples sintered by SPS have small simple shapes, such as disks and plates, because these shapes are suitable for investigating the characteristics of SPS sintered materials. Long rods with high relative density are difficult to obtain using the SPS process with axial compressive load because of the associated high cost and low productivity. The spark plasma extrusion (SPE) process is suitable for fabricating FG rods with a high aspect ratio (length-to-diameter ratio) (Morsi, et al., 2009, Morsi, et al., 2010). The SPE process is an extension of the SPS process. SPE enables consolidation and a reduction in diameter of the FG rods at the same time (Lu, el at., 2014). Therefore, SPE has high productivity compared with the conventional method involving hot extrusion, as used in hydraulic presses.

In this study, FG rods with three layers in the radial direction were fabricated by the SPE process with extrusion ratios of 2.3 (from $d_{i}=15 \mathrm{~mm}$ to $d_{o}=10 \mathrm{~mm}$ ) and 3.5 (from $d_{i}=15 \mathrm{~mm}$ to $d_{o}=8 \mathrm{~mm}$ ). The FG consisted of a pure Ti compact in the center, a layer of $\mathrm{Ti}$ containing $15 \mathrm{vol} \% \mathrm{TiB}(15 \mathrm{TiB} / \mathrm{Ti}$ composite) in the middle, and a layer of $\mathrm{Ti}$ containing $25 \mathrm{vol} . \% \mathrm{TiC}$ (25TiC/Ti composite) on the outside. The 15TiB/Ti and $25 \mathrm{TiC} / \mathrm{Ti}$ composite layers exhibited high tensile strength and good wear resistance, respectively. The effect of the extrusion ratios on the extrusion behavior, the microstructure, and the tensile properties of the FG rods was investigated.

\section{Experimental}

\subsection{Staring powders}

Hydride-dehydride pure Ti powders (HDH 45) with a particle size of less than $45 \mu \mathrm{m}$ were used as the matrix material. The reinforcement materials were $\mathrm{TiB}_{2}$ and $\mathrm{TiC}$ particles with particle sizes of $1-2 \mu \mathrm{m}$. SEM micrographs of these particles are shown in Fig. 1.

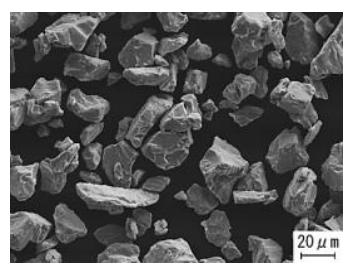

(a) Hydride-dehydride pure Ti

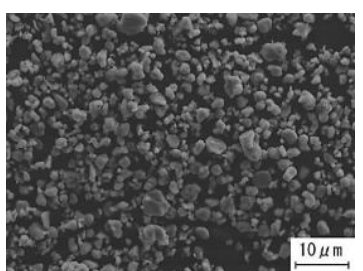

(b) $\mathrm{TiB}_{2}$

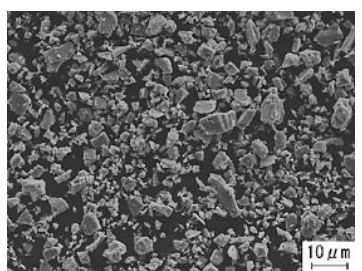

(c) $\mathrm{TiC}$

Fig.1 SEM micrographs of matrix and reinforcement particles.

\subsection{Fabrication of FG rod by SPE process}

The FG rods consisted of three layers: pure Ti compact in the center, Ti containing 15 vol.\% TiB in the middle, and Ti containing 25 vol.\% TiC on the outside, as shown in Fig. 2 (a). First, two thin wall pipes with different diameters of $12 \mathrm{~mm}$ and $8 \mathrm{~mm}$ were placed in the die, as shown in Fig. 2 (b). Then, the spaces between the pipes were filled with each starting powder, and the pipes were pulled out from the die. Figure 3 shows schematic diagrams of tapered dies for the SPE process and the die for the SPS process. Extrusion was carried out at extrusion ratios (cross-sectional area before extrusion/cross-sectional area after extrusion) of 2.3 (from $d_{i}=15 \mathrm{~mm}$ to $d_{o}=10 \mathrm{~mm}$ ) and 3.5 (from $d_{i}=15 \mathrm{~mm}$ to $d_{o}=$ $8 \mathrm{~mm}$ ) and at a taper ratio of 1:1.5 at the transition region. The SPE and SPS process conditions were a heating speed of $20{ }^{\circ} \mathrm{C} / \mathrm{min}$, a temperature of $1000{ }^{\circ} \mathrm{C}$, and a pressure of $50 \mathrm{MPa}$. When the temperature of the die reached $1000{ }^{\circ} \mathrm{C}$, an extrusion force was applied to the lower punch as shown in Figs.3 (a) and (b). For the SPS process with axial compressive load, the load application and the heating were started simultaneously. The pressure in the furnace was $<5 \mathrm{~Pa}$ during the SPE and SPS processes. 


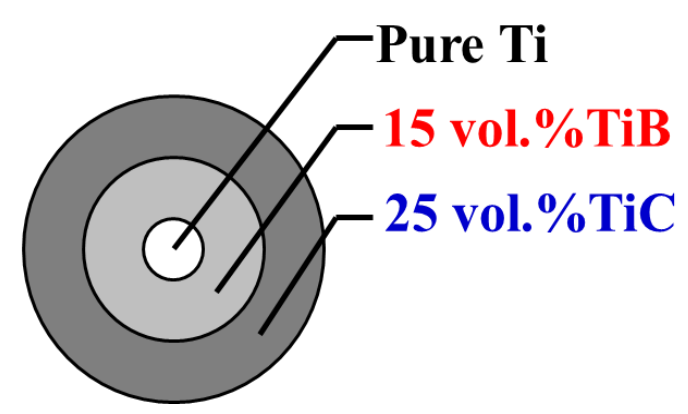

(a) Material composition in FG rod

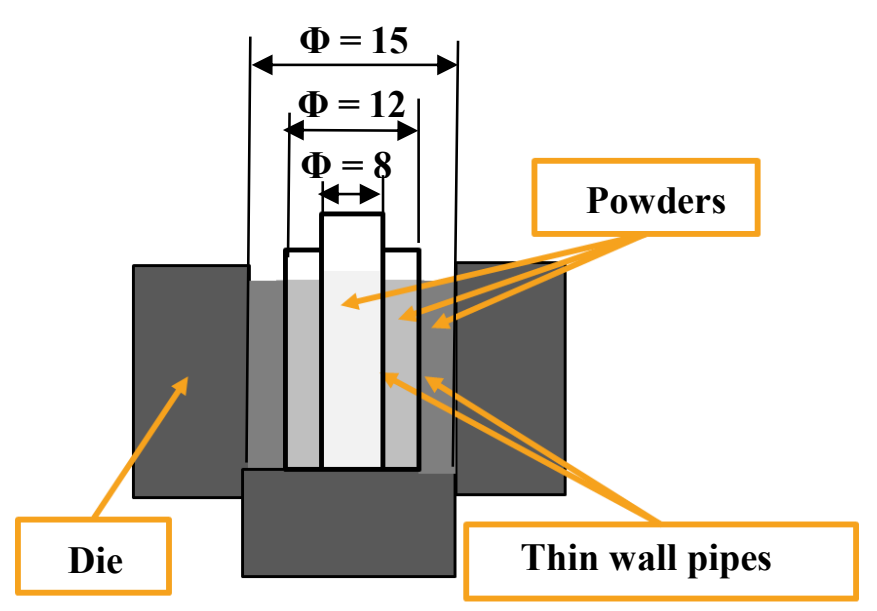

(b) Powders filled into the die

Fig. 2 Material composition in FG rod and powders filled into the die.

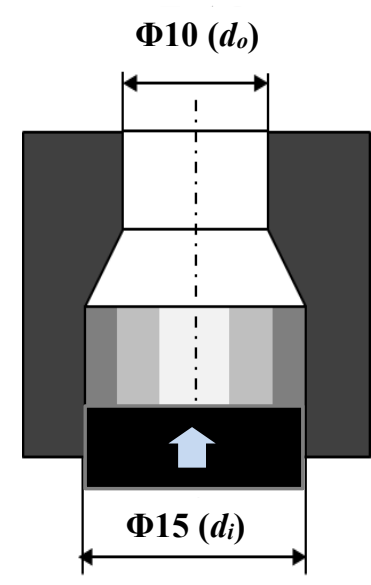

(a) Extrusion ratio 2.3

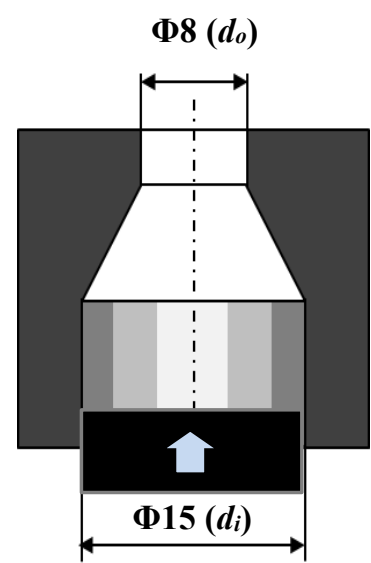

(b) Extrusion ratio 3.5

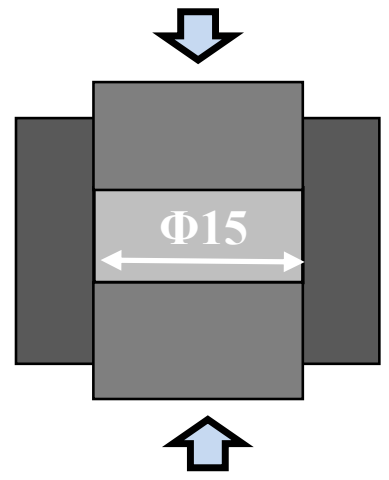

(c) SPS process

Fig. 3 Schematic diagrams of tapered dies for SPE process and die for SPS process.

Tensile tests of single materials (pure Ti compact, and 15TiB/Ti and 25TiC/Ti composites) extruded with an extrusion ratio of 3.5 were conducted at a crosshead speed of $0.1 \mathrm{~mm} / \mathrm{min}$ using an Instron testing machine. The elongation of the specimen was measured using a strain gauge with a gauge length of $1 \mathrm{~mm}$. The tensile test specimen geometry is shown in Fig. 4.

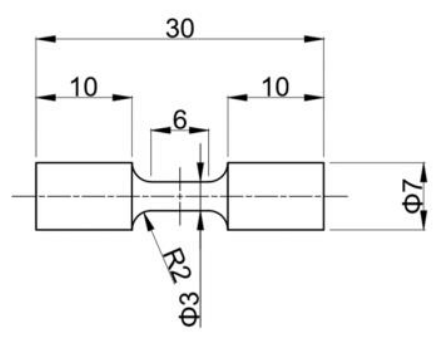

Fig. 4 Tensile test specimen.

\section{Results and discussion}

\subsection{Extrusion behavior of FG rods by SPE process}

Figure 5 shows the cross-sections and appearances of FG rods with extrusion ratios of 2.3 and 3.5 fabricated by the SPE process. FG rods consisted of three concentric rings in the cross-section. The FG rods with lengths of over 40 
mm could be obtained. The extrusion speeds of the FG rods are shown in Fig. 6. The FG rod with an extrusion ratio of 2.3 showed higher extrusion speed than that of the FG rod with an extrusion ratio of 3.5. In the case of no friction between the die surface and the material, the extrusion pressure $\sigma_{e x}$ when a using tapered die can be expressed as:

$$
\sigma_{e x}=2 k \ln \left(\frac{d_{i}}{d_{o}}\right)
$$

where $k$ is the shear yield stress, and $d_{1}$ and $d_{2}$ are die inlet diameter and die exit diameter, respectively (Miyagawa, 1981). Therefore, the extrusion pressure depends on the value of the term $\ln \left(d_{i} / d_{o}\right)$. The values for the extrusion ratios of 2.3 and 3.5 are -0.405 and -0.629 , respectively. The extrusion with an extrusion ratio of 3.5 needed higher compressive pressure than that with an extrusion ratio of 2.3. This indicates that it might be easier to fabricate FG rods in a shorter time using extrusion with an extrusion ratio of 2.3 .

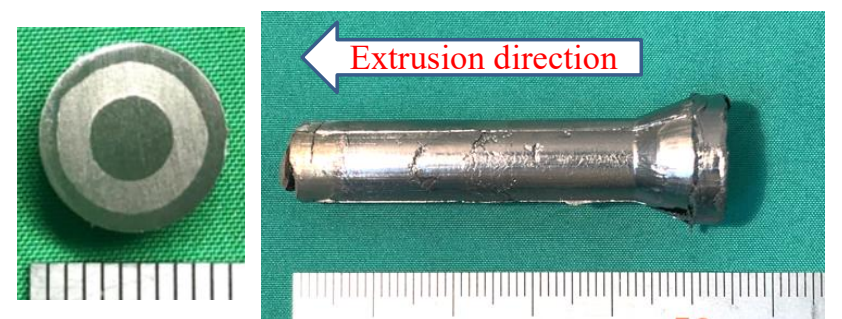

(a) Extrusion ratio 2.3
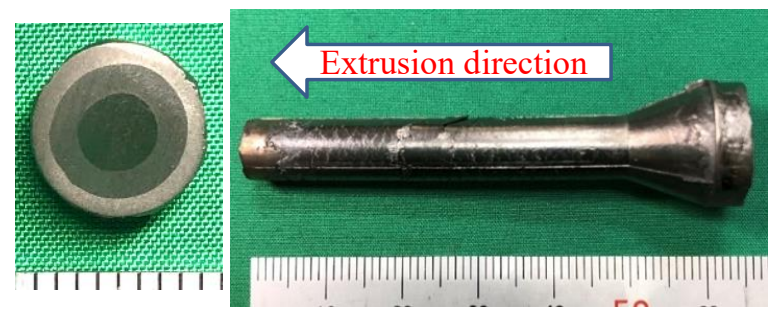

(b) Extrusion ratio 3.5

Fig.5 Cross-sections and appearances of the FG rods fabricated by SPE process with different extrusion ratios.

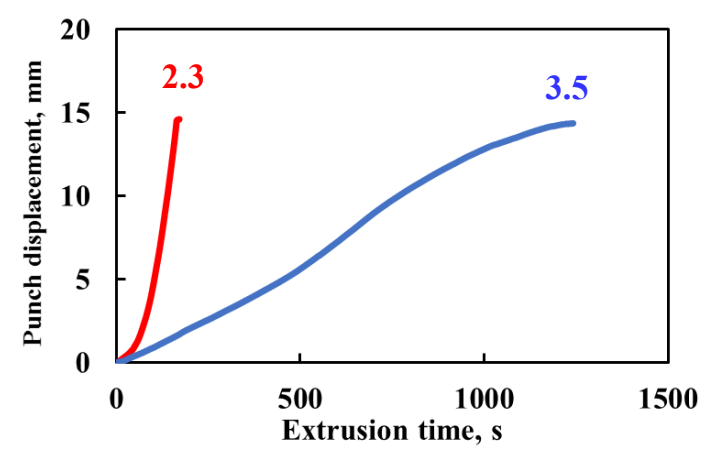

Fig.6 Relationship between punch displacement and extrusion time of SPE process with extrusion ratios of 2.3 and 3.5.

\subsection{Microstructures of FG rods fabricated by SPE process}

The cross-sections and microstructures at the composite layer interfaces of the FG rods extruded with the extrusion ratios of 2.3 and 3.5 are shown in Figs. 7 and 8. From the cross-sectional photographs, each composite layer maintained a constant thickness in the extrusion direction. In the SEM micrographs at the composite layer interface, the composite layer interfaces can be clearly observed. These indicated that the materials flowed along the extrusion direction without powder mixing at the composite layer interfaces. No voids or cracks were observed at the interfaces.
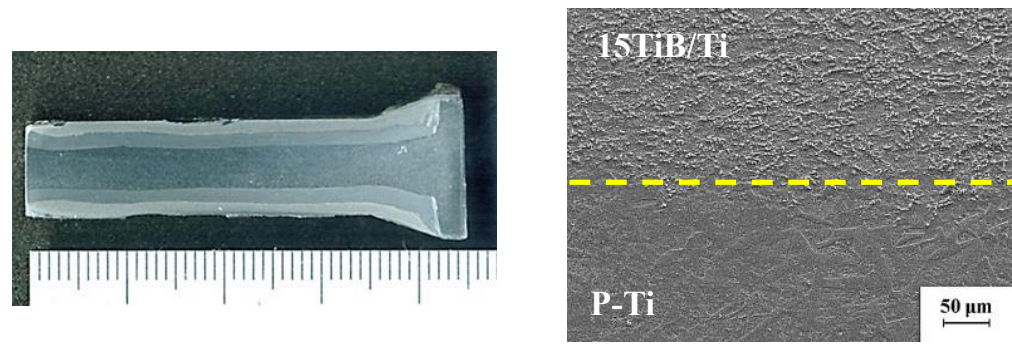

(a) Cross-section

(b) Interface between pure $\mathrm{Ti}$ and $\mathrm{TiB} / \mathrm{Ti}$

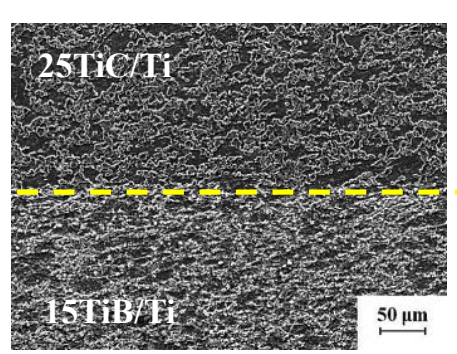

(c) Interface between $\mathrm{TiB} / \mathrm{Ti}$ and $\mathrm{TiC} / \mathrm{Ti}$ Fig. 7 Cross-section and microstructures at the interfaces between each layer (extrusion ratio 2.3). 


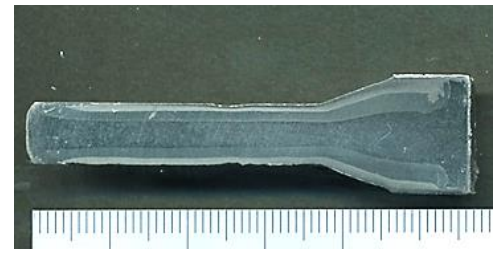

(a) Cross-section

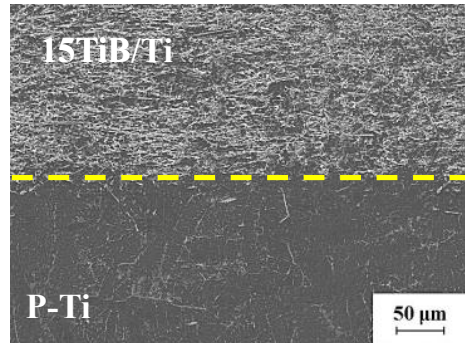

(b) Interface between pure $\mathrm{Ti}$ and $\mathrm{TiB} / \mathrm{Ti}$

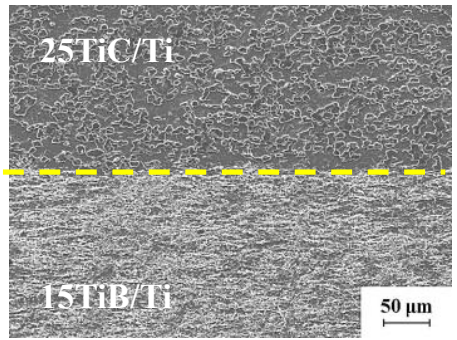

(c) Interface between $\mathrm{TiB} / \mathrm{Ti}$ and $\mathrm{TiC} / \mathrm{Ti}$

Fig. 8 Cross-section and microstructures at the interfaces between each layer (extrusion ratio 3.5).

\subsection{Relative density of pure $\mathrm{Ti}$ compact, $\mathrm{TiB} / \mathrm{Ti}$, and $\mathrm{TiC} / \mathrm{Ti}$ composites}

Because it was difficult to evaluate the relative densities of FG rods, the relative densities of extruded single materials were evaluated. The relative densities of the materials were measured by the Archimedes method using deionized water immersion. Table 1 shows the relative densities of the materials. For the pure Ti and 15TiB/Ti composite, there was not much difference in the relative densities with the different processing methods. However, the relative density of $25 \mathrm{TiC} / \mathrm{Ti}$ composite in the SPE process was higher than that in the SPS process. This is due to the presence of voids at the $\mathrm{TiC}$ agglomerates in the $25 \mathrm{TiC} / \mathrm{Ti}$ composite fabricated by the SPS process.

Table 1 Relative densities of materials consolidated by different processing methods.

\begin{tabular}{|c|c|c|c|}
\hline Process & Pure $\mathrm{Ti}$ & $15 \mathrm{TiB} / \mathrm{Ti}$ & $25 \mathrm{TiC} / \mathrm{Ti}$ \\
\hline SPS Process & $99.6 \%$ & $99.9 \%$ & $97.7 \%$ \\
\hline SPE process (extrusion ratio 2.3) & $99.8 \%$ & $99.8 \%$ & $98.4 \%$ \\
\hline SPE process (extrusion ratio 3.5) & $99.5 \%$ & $99.7 \%$ & $98.6 \%$ \\
\hline
\end{tabular}

\subsection{Variation of cross-sectional area ratio of each composite layer in the FG rods.}

Next, the variation of the cross-sectional area ratio of each composite layer in the FG rods with the extrusion ratios was evaluated. The cross-sectional area ratio was calculated by the following formula: “

$$
\text { Cross-sectional area ratio }[\%]=\frac{\text { Cross-sectional area of each composite layer }\left[\mathrm{mm}^{2}\right]}{\text { Cross-sectional area of } \mathrm{FG} \mathrm{rod}\left[\mathrm{mm}^{2}\right]} \times 100
$$

Figure 9 shows the variation of the cross-sectional area ratios before and after the SPE process with different extrusion ratios. The cross-sectional area ratio of the pure Ti layer decreased with increasing extrusion ratio after the extrusion, but the cross-sectional area ratio of the $25 \mathrm{TiC} / \mathrm{Ti}$ composite layer increased. The cross-sectional area ratio of the $15 \mathrm{TiB} / \mathrm{Ti}$ composite layer was almost the same before and after the extrusion. The pure Ti composite layer showed a much better ductility compared to the composite layers containing $\mathrm{TiB}$ and $\mathrm{TiC}$. Therefore, the results indicated the occurrence of extensive plastic deformation of the pure Ti composite layer during extrusion.

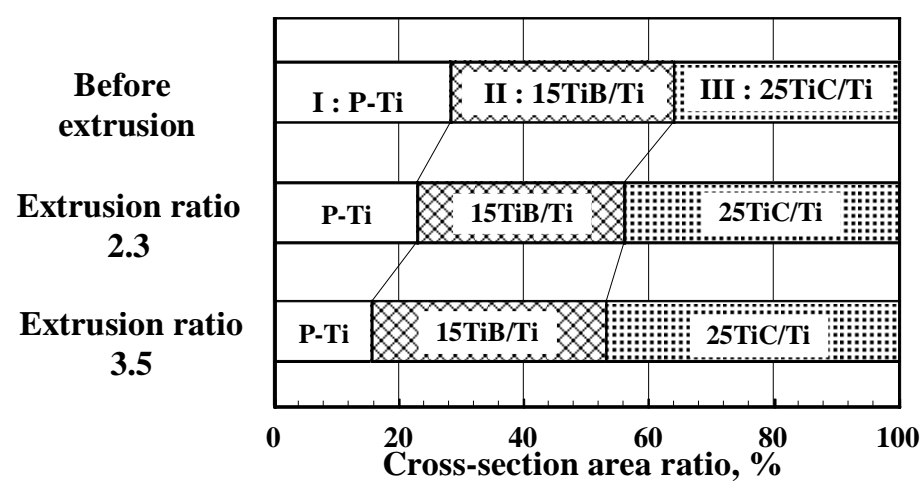

Fig. 9 Variation of cross-sectional area ratios before and after SPE process with different extrusion ratios. 


\subsection{Distribution of $\mathrm{TiC}$ particles and orientation of $\mathrm{TiB}$ whiskers after extrusion}

Figures 10 and 11 present SEM micrographs of and 25TiC/Ti and 15TiB/Ti composites fabricated by SPS process and $25 \mathrm{TiC} / \mathrm{Ti}$ and $15 \mathrm{TiB} / \mathrm{Ti}$ composite layers of the $\mathrm{FG}$ rods fabricated by SPE process. For the 25TiC/Ti composite fabricated by the SPS process, large TiC agglomerations were observed compared to the composites fabricated by the SPE process. On the other hand, for the FG rods fabricated by the SPE process, the sizes of the TiC agglomerations were smaller than in the compacts fabricated by axial compression and decreased with increasing extrusion ratio. This is because sufficient material flow occurred in the extrusion direction during extrusion, and the TiC particles were uniformly distributed along the extrusion distribution. From Fig. 11(a), large TiB clusters in the compact fabricated by the axial compassion can be observed. However, the sizes of the TiB clusters in the FG rods fabricated by the SPE process were smaller than those fabricated by the SPS process. The sizes of the TiB clusters decreased and the number of TiB whiskers increased with increasing extrusion ratio. The sizes of the TiB clusters decreased due to sufficient material flow in the extrusion direction. It is thought that $\mathrm{TiB}$ whiskers are generated by direct contact between the $\mathrm{Ti}$ and $\mathrm{TiB}_{2}$ particles. Therefore, $\mathrm{TiB}_{2}$ particles have a greater chance of making contact with Ti particles during extrusion, resulting in the generation of many TiB whiskers (Sahay, el at., 1999; Panda, el at., 2003).

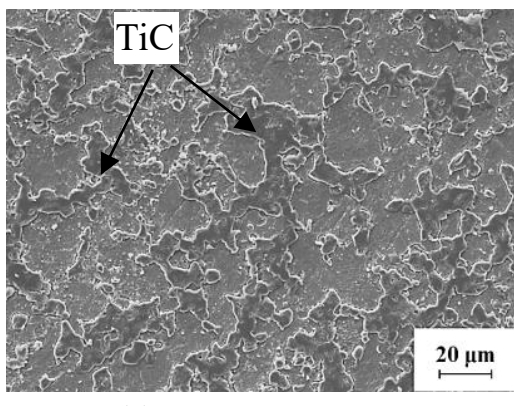

(a) SPS process

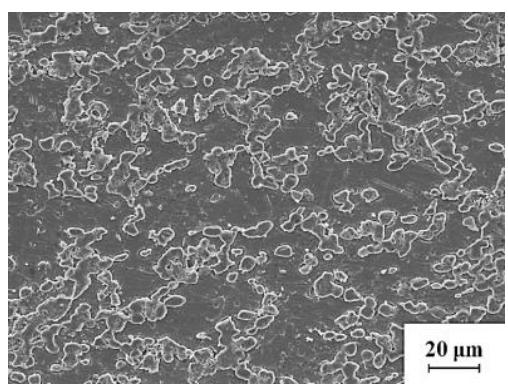

(b) Extrusion ratio 2.3

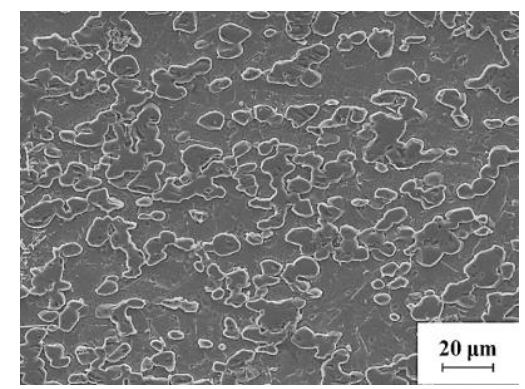

(c) Extrusion ratio 3.5

Fig.10 SEM micrographs of 25TiC/Ti composite layers.

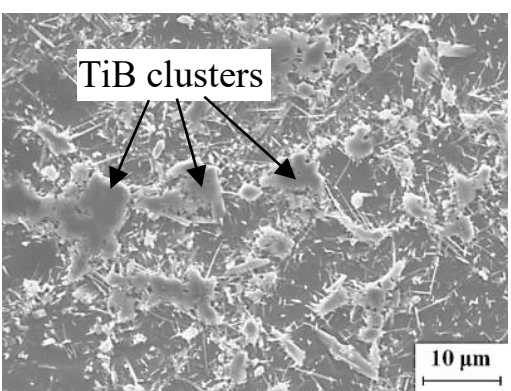

(a) SPS process

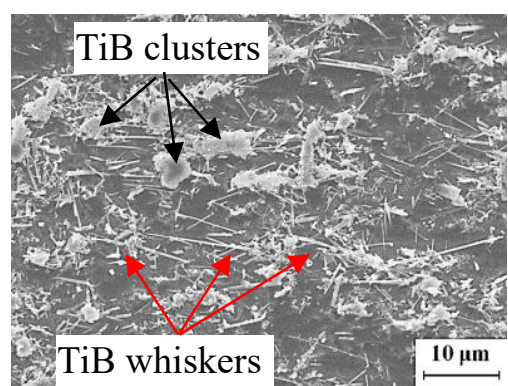

(b) Extrusion ratio 2.3

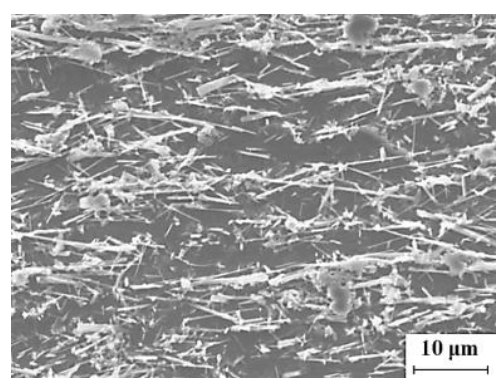

(c) Extrusion ratio 3.5

Fig.11 SEM micrographs of 15TiB/Ti composite layers.

From Fig. 11(a), the TiB whiskers in the compact fabricated by axial compression were randomly dispersed and oriented. However, the TiB whiskers in the FG rods fabricated by extrusion were oriented parallel to the extrusion direction, as shown in Fig. 11(c). The variation of the TiB whisker orientation with the processing method and extrusion ratio was investigated. Two hundred and fifty TiB whiskers were randomly selected from each specimen, and the angles between the TiB whiskers and the extrusion direction were measured, as shown in Fig. 12 (a). Figure 12(b), (c) and (d) show the relationship between the frequency of the TiB whiskers and the angle of whiskers relative to the extrusion direction. From Fig. 12 (b), the angles of the TiB whiskers in the compacts fabricated by the SPS process were randomly distributed from 0 to $\pi / 2$. With increasing extrusion ratio, the angles of the TiB whiskers shifted to lower angles. This means that the SPE process changed the orientation distribution of the TiB whiskers significantly. The solid-line curve represents the probability density function $P(\theta)$ describing the distribution of TiB whisker orientation angles (Fukuda, el at., 1982; Guo, el at., 2012; Ma, el at., 2017). The function was derived from the results of hot extrusion of a TiBreinforced Ti matrix composite fabricated by casting. The probability density function $P(\theta)$ can be expressed as: 


$$
P(\theta)=\frac{2 / \pi}{n^{3} \sin ^{2} \theta+n^{-3} \cos ^{2} \theta}
$$

where the values of $n\left(d_{i} / d_{o}\right)$ are calculated to be 1.5 and 1.875 with extrusion ratios of 2.3 and 3.5 , respectively. For the SPS process, TiB whiskers were randomly oriented in all directions and the value of $P(\theta)$ indicated constant due to the random orientation of the TiB whiskers as shown in Fig. 12 (b). The peaks of the $P(\theta)$ value were found at the 0 radian. From Figs. 12 (c) and (d), the frequency and the $P(\theta)$ values decreased with increasing the orientation angle $\theta$. the frequency of the TiB whiskers and the $P(\theta)$ values function had nearly the same tendency.

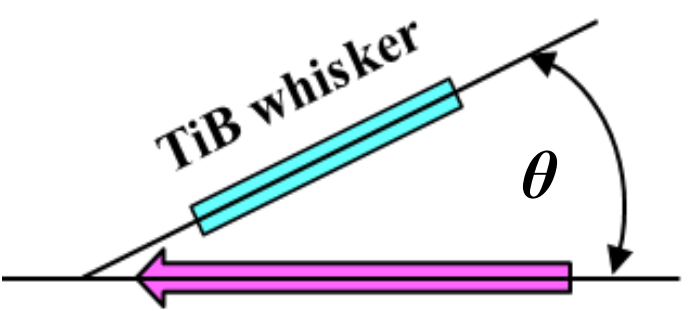

Extrusion direction

(a) Angle $\theta$ between TiB whisker and extrusion direction

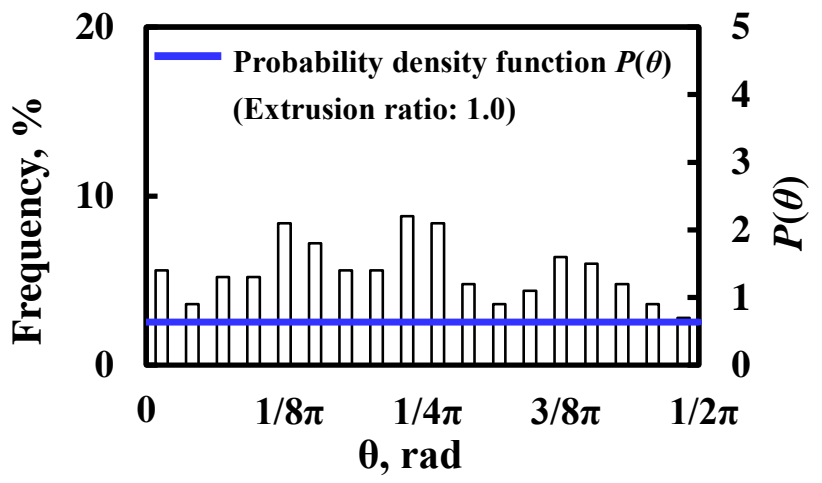

(b) SPS process

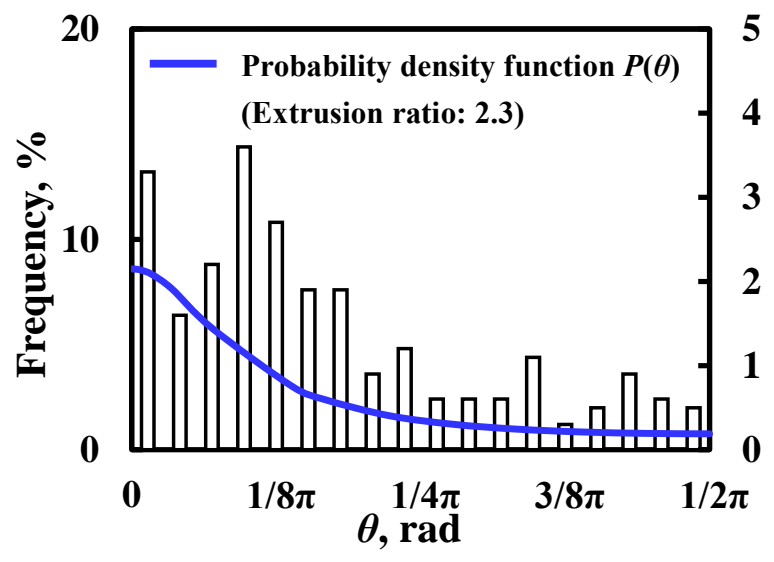

(c) Extrusion ratio 2.3

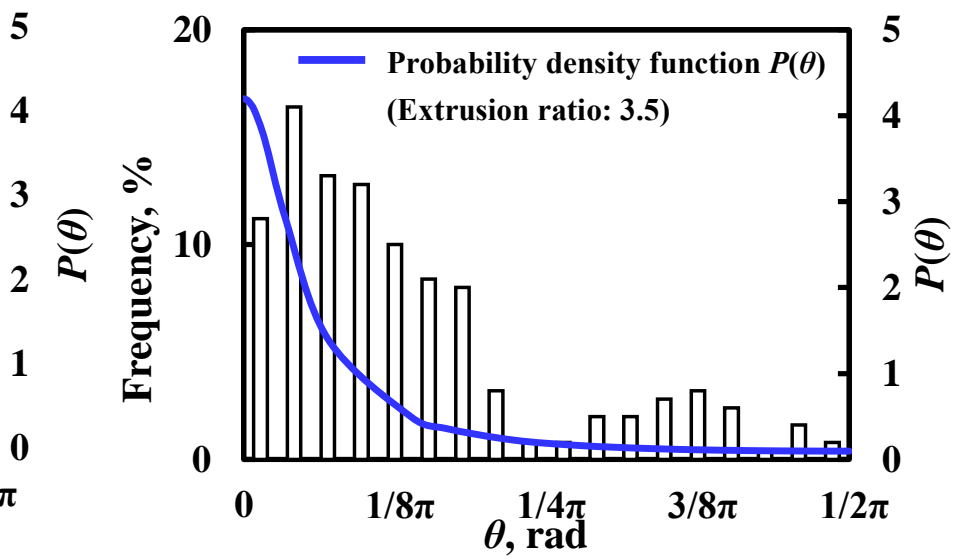

(d) Extrusion ratio 3.5

Fig. 12 Variation of TiB whisker orientation with the extrusion ratio.

\subsection{Tensile strengths and elongations of the pure $\mathrm{Ti}, 15 \mathrm{TiB} / \mathrm{Ti}$ and $25 \mathrm{TiC} / \mathrm{Ti}$ composites fabricated by SPE and SPS processes}

The tensile strengths and elongations of the pure Ti compact and the 15TiB/Ti and 25TiC/Ti composites fabricated by the SPE and SPS processes are shown in Fig. 13. The tensile strength of the 15TiB/Ti composite fabricated by the SPE process increased significantly compared to the composite fabricated by the SPS process. The elongation of the $15 \mathrm{TiB} / \mathrm{Ti}$ composite fabricated by the SPE process was slightly higher than that of the composite fabricated by the SPS process. The SEM micrographs of the cross-sections of the tensile test specimens near the fractured surfaces with different processing methods are shown in Fig. 14. From Fig. 14 (a), the cracks in the 15TiB/Ti composite fabricated by the SPS process were initiated at the TiB clusters between the matrix particles and then propagated into the TiB clusters between them (da Silva, el at., 2006). For the specimen fabricated by the SPE process, a crack in the TiB whisker could be observed, as shown in Fig. 14 (b), but the crack did not propagate into the matrix. Furthermore, there was little evidence of TiB whisker pull-out on the fracture surfaces. Because there is no intermediate phase with low between titanium and TiB, and TiB has excellent crystallographic compatibility with titanium (Ravichandran, el at., 2004). Therefore, the increase in the tensile strength was attributed to the transformation from the TiB clusters to TiB whiskers and their orientation along the extrusion direction. There was a small difference in the tensile strengths of the pure Ti compacts 
fabricated by the SPS and SPE processes, and also the 25TiC/Ti composites fabricated by the SPS and SPE processes. The tensile strengths of the FG rods with the extrusion ratio of 3.5 fabricated by the SPE and SPS processes can be calculated, using the obtained tensile strength of each material and area ratio, to be $870 \mathrm{MPa}$ and $763 \mathrm{MPa}$, respectively. The increase in the thickness of the $15 \mathrm{TiB} / \mathrm{Ti}$ composite layer may have further improved the tensile strength of the FG rod fabricated by the SPE process. The elongation of the pure Ti compact fabricated by the SPE process was obviously higher than that fabricated by the SPS process due to the grain growth of the Ti particles. The elongation of the $25 \mathrm{TiC} / \mathrm{Ti}$ composites fabricated by the SPE process was also higher than that fabricated by the SPS process due to the distribution of TiC particles in the Ti matrix. Therefore, the ductility of the FG rod can be improved by the SPE process.

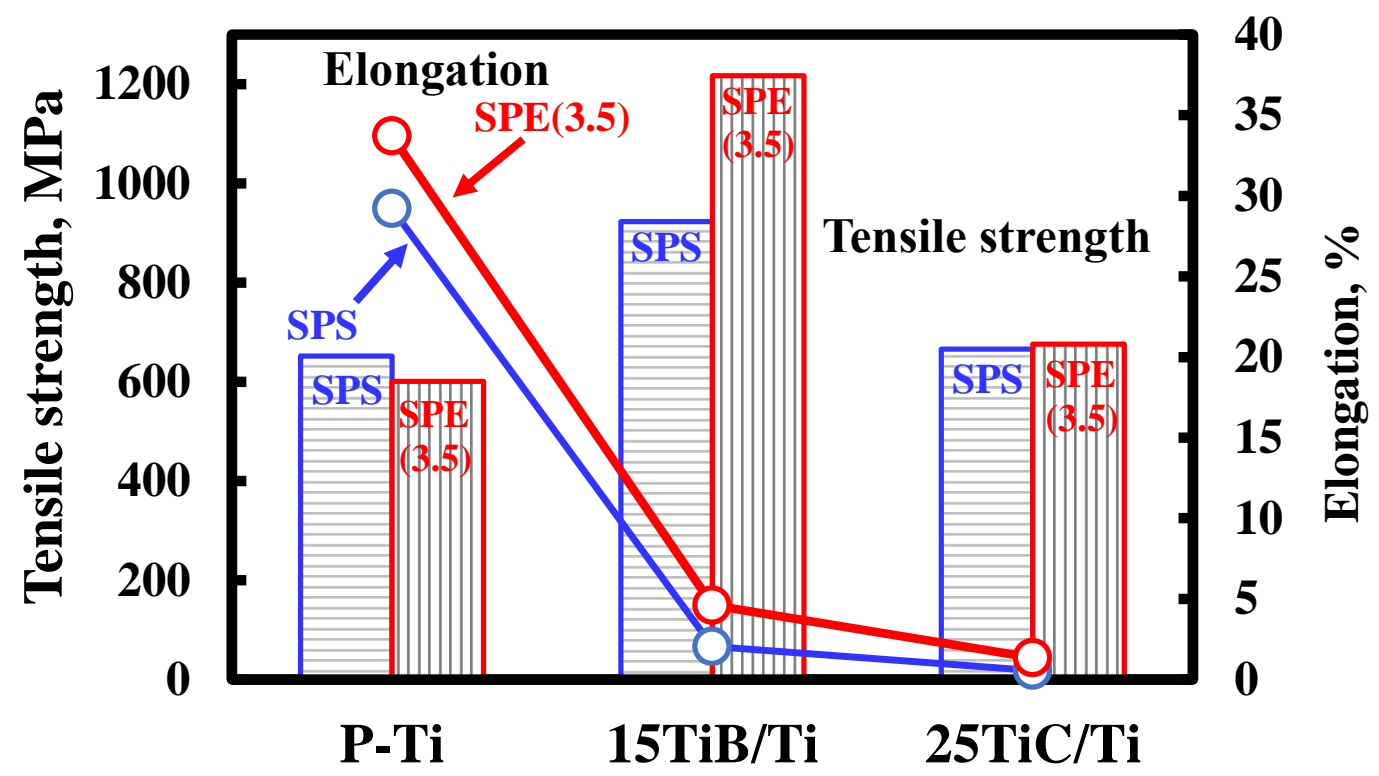

Fig.13 Tensile strengths and elongations of pure Ti compacts, and 15TiB/Ti and $25 \mathrm{TiC} / \mathrm{Ti}$ composites fabricated by SPS and SPE processes.

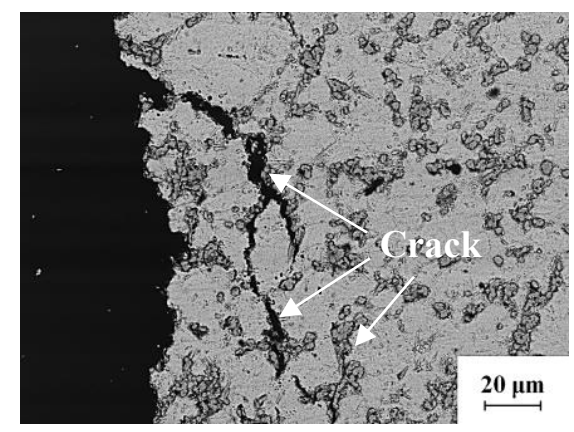

(a) SPS process

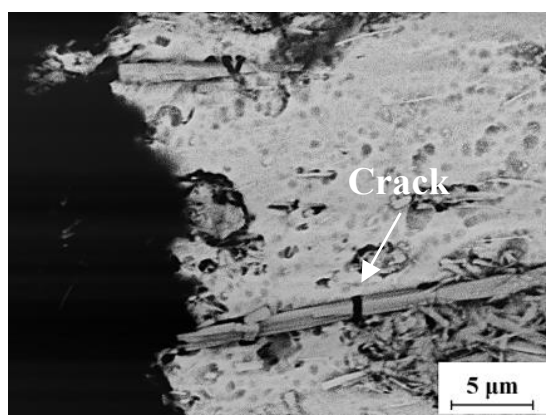

(b) SPE process

Fig.14 SEM micrographs of tensile test specimens of $15 \mathrm{TiB} / \mathrm{Ti}$ composites near fractured surface with different processes.

\section{Conclusions}

Functionally graded (FG) rods with three layers in the radial direction were prepared by a spark plasma extrusion (SPE) process with extrusion ratios of 2.3 and 3.5. The resulting FG rods were characterized in terms of the extrusion behavior, microstructures and tensile properties. The following conclusions can be drawn:

1) FG rods that consisted of pure $\mathrm{Ti}$ in the center, a $15 \mathrm{TiB} / \mathrm{Ti}$ composite layer in the middle, and a $25 \mathrm{TiC} / \mathrm{Ti}$ composite layer on the outside could be obtained using the SPE process. The FG rods with lengths of over 40 mm and diameters of 8 and $10 \mathrm{~mm}$ exhibited high relative densities.

2) The cross-sectional area ratio of the pure Ti layer decreased and that of the $25 \mathrm{TiC} / \mathrm{Ti}$ composite layer increased with 
increasing extrusion ratio after the SPE process. The variation of the area ratio depended on the ductility of the material. 3) During the SPE process, $\mathrm{TiC}$ agglomerations in the $25 \mathrm{TiC} / \mathrm{Ti}$ composite layer disintegrated, and $\mathrm{TiC}$ particles were uniformly distributed in the matrix. The TiB clusters were transformed into TiB whiskers, and the TiB whiskers were oriented preferentially along the extrusion direction.

4) The $15 \mathrm{TiB} / \mathrm{Ti}$ composite fabricated by the SPE process exhibited higher tensile strength than that fabricated by the SPS process due to the orientation of the TiB whiskers parallel to the extrusion direction. The ductilities of the pure Ti compact, $15 \mathrm{TiB} / \mathrm{Ti}$ and $25 \mathrm{TiC} / \mathrm{Ti}$ composites can be improved by the SPE process.

5) It was found that FG rods having high tensile strength, good wear resistance, and high ductility were fabricated by the SPE process.

\section{Acknowledgments}

The authors gratefully acknowledge the AMADA Foundation under Grant No.2016012 for financial support of this work.

\section{References}

Chmielewski, M., and Pietrzak, K., Metal-ceramic functionally graded materials - manufacturing, characterization, application, Bulletin of the Polish Academy of Science Technical Science, Vol. 64, No.1 (2016), pp.151-160.

da Silva, A.A.M., dos Santos, J.F., and Strohaecker, T.R., An investigation of the fracture behavior of diffusion-bonded Ti6Al4V/TiC/10p, Composites Science and Technology, Vol.66, No.13 (2006), pp.2063-2068.

Fukuda, H., Chou, T. W., A probabilistic theory of the strength of short-fibre composites with variable fibre length and orientation, Journal of Materials Science, Vol.17, No. 4 (1982), pp.1003-1011.

Guo, X., Wang, L., Wang, M., Qin, J., Zhang, D., and Lu, W., Effects of degree of deformation on the microstructure, mechanical properties and texture of hybrid-reinforced titanium matrix composites, Acta Materialia, Vol. 60, Issue 5 (2012), pp. 2656-2667.

Izui, H., Toen, K., Kamegawa, S., and Komiya, Y., Dry sliding wear behavior of TiB/Ti and TiC/Ti composites, Mechanical Engineering Journal, DOI: 10. 1299/mej. 17-00523.

Kamegawa, S., Izui, H., Komiya, Y., Kobayashi, K., and Arimoto R., Dependence of matrix powder morphology and size on tensile and wear properties of Ti matrix composites prepared by spark plasma sintering, TMS 2015 Annual Meeting Supplemtal Proceedings, (2015), pp.203-210.

Kieeback, B., Neubrand, A., and Riedel, H., Processing techniques for functionally graded materials, Materials Science and Engineering, Vol. A362, No.1 (2003), pp.81-105.

Lu,H., Zhang, D., Gabbitas, B., Yang, F., and Matthews, S., Synthesis of a TiBw/Ti6A14V composite by powder compact extrusion using a blended powder mixture, Journal of Alloys and Compounds, Vol.606, No.2 (2014), pp.262-268.

Ma, F., Lu, S., Liu, P., Li, W., Liu, X., Chen, X., and Zhang, K., Evolution of strength and fibers orientation of a shortfibers reinforced Ti-matrix composite after extrusion, Materials \& Design, Vol.126, No.7 (2017), pp. $297-304$.

Miyagawa, M., Introduction to dynamic of the plasticity processing, the Japan Institute of Metals, Vol. 20, No. 2 (1981), pp.161-126, (in Japanese).

Miyamoto, Y., Kaysser, W.A., Rabin, B.H., Kawasaki, A., and Ford, R.G., Functionally Graded Materials, p.161, Kluwer Academic Publishers.

Morsi, K., El-Desouky, A., Johnson, B., Mar, A., and Lanka, S., Spark plasma extrusion (SPE): Prospects and potential, Scripta Materialia, Vol. 61, No.4 (2009), pp. 395-398.

Morsi, K., Esawi, A.M.K., Borah, P., Lanka, S., Sayed, A., and Taher, M., Properties of single and dual matrix aluminumcarbon nanotube composites processed via spark plasma extrusion (SPE), Materials Science and Engineering A, Vol. A527, Issues 21-22 (2010), pp.5686-5690.

Panda, K. B., and Ravichandran, K.S., Synthesis of Ductile Titanium-Titanium Boride (Ti-TiB) Composites with a BetaTitanium Matrix: The Nature of TiB Formation and Composite Properties, Metallurgical and Materials Transactions A, Vol. 34A, No. 6 (2003), pp.1371-1385.

Ravichandran, K.S., Panda, K. B., and Sahay, S. S., TiBw-reinforced Ti composites: Processing, properties, Application prospects, and research needs, JOM, Vol. 56, No. 5 (2004), pp.42-48. 
Sahay, S.S., Ravichandran, K.S., and Atri, R., Evolution of microstructure and phases in in situ processed Ti-TiB composites containing high volume fraction of TiB whiskers, Journal of Materials Research, Vol. 14, No. 11 (1999), pp.4214-4223.

Tokita, M., Development of square-shaped large-size WC/Co/Ni system FGM fabricated by spark plasma sintering (SPS) method and its industrial application, Materials Science Forum, Vols. 492-492, No.1 (2005), pp. 711-718.

Watanabe, T., Yamamoto, S., Fukase, K., Matsuda, N., Izui, H., and Okano, M., Processing of FGM with five concentric layers by spark plasma sintering and analysis by the finite element method, Journal of Japan Society of Powder and Powder Metallurgy, Vol.55, No. 5 (2008), pp.365-372, (in Japanese). 